\author{
J. Nowacki, A. Sajek* \\ West Pomeranian University of Technology, Szczecin, Poland \\ *adam.sajek@zut.edu.pl
}

\title{
TRENDS OF JOINING COMPOSITE AISi-SiC FOAMS
}

\begin{abstract}
The paper consist of characterization of the essence of structure, properties and application of AlSi-SiC composite foams as well as limitations and possibilities of their joining. Porous structure with porosity up to $80 \%$ and exceptional properties of aluminium foams are the reason of their numerous application and interest of their joining. Consideration of methods of welding, soldering and gluing AlSi9-SiC10 composite foams, the joint structure, and properties. Recommendations for surface preparation of foam, and different joining procedures aimed at control the porosity of the foam and glued surface roughness were established. Result of EDS and XRD investigations of the AlSi9-SiC10 composite foams joint were considered.
\end{abstract}

Keywords: aluminium foams; composite AlSi-SiC foams; metallic foams joining; porous materials

\section{INTRODUCTION}

Aluminium foams produced by means of powder metallurgy, vacuum and electrochemical deposition, casting as well as laser beam foaming methods have unique properties: low density, energy absorption, vibration damping and good thermal insulation [1]-[3]. The density of aluminium foams ranges from 0,15 to $0,5 \mathrm{~g} / \mathrm{cm}^{3}$ at the porosity of $75-$ 95\%, while their structure (Fig. 1) and properties depend on the density and the ratio between open and closed pores. Foam density determines the size and shape of foam cells, their distribution and anisotropy. Foams with a higher density, have smaller pores which are also distributed more evenly. When density decreases, smaller pores are absorbed by the bigger ones, which results in an uneven distribution of the pores. Foams with a higher density have better mechanical properties - the higher the density, the better the energy absorption, especially in foams with closed pores. The mechanical properties of AlSi9-SiC10 foams (Tab. 1.) make them an attractive construction material in vehicle manufacturing industry, machine tools construction, electrotechemical industry, chemical apparatus and building construction [4]. Employing foams for car body panelling in order to increase passengers' safety is also being considered [5], [6]. In machine-building industry, aluminium foams are used as oscillation, noise and vibration damping insulators, bumper elements, heat exchangers and fire-proof ship bulkheads [7], [8]. 
Table 1. Strength of AISi9 and AISi9-SiC10 foams

\begin{tabular}{cccc}
\hline Foam type & $\begin{array}{c}\text { Porosity } \\
\%\end{array}$ & $\begin{array}{c}\text { Yield strength at } \mathrm{R}_{\mathrm{p} 0.2} \\
\mathrm{MPa}\end{array}$ & $\begin{array}{c}\text { Static tensile strength } \mathrm{R}_{\mathrm{m}} \\
\mathrm{MPa}\end{array}$ \\
\hline AlSi9 & 75 & 1.5 & 3.3 \\
AlSi9 & 85 & 1.2 & 3.0 \\
AlSi9-SiC10 & 75 & 1.7 & 3.5 \\
AlSi9-SiC10 & 85 & 1.6 & 3.1 \\
\hline
\end{tabular}
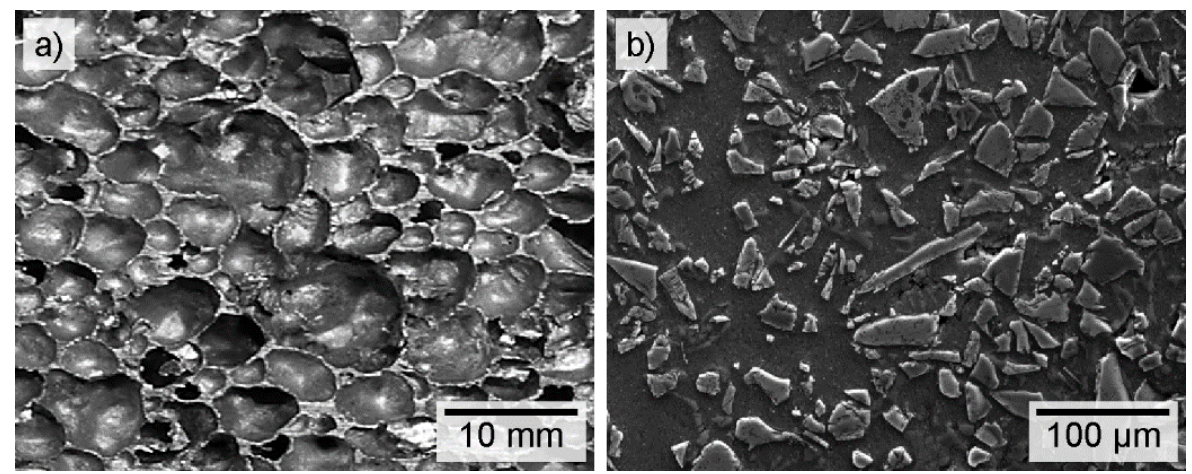

Fig.1. LM image of the structure of AISi9-SiC10 foam; pores enclosed by cell walls (a), $\mathrm{SiC}$ particles in cell walls (b)

The cellular structure and high porosity of AlSi9-SiC10 foams gives rise to joining limitations in the following areas:

- preparation of the edge surfaces to be joined and their geometry evaluation,

- varying size of the soldering gap,

- high filler metal consumption due to foam cells infiltration,

- thermal deformation of the foam walls,

- joints mechanical properties testing methodology.

The optimisation of joining of composite aluminium foams includes minimisation of the mass of a joint while retaining its maximum strength.

\section{ARC WELDING}

The few available publications of welding on the structure and properties of joints. The majority of sources focus on the assessment of the possibility to produce welded joints in aluminium foams and non-porous materials.

Arc welding of aluminium foams leads to the collapse of foam structure as a result of thermal deformation of the thin cell walls. In order to eliminate this phenomenon, it is necessary to lessen the porosity of the foam surface by means of pressing down heated foam edges, which deforms the cells and increases their density.

Buzer et al. [9] investigated the influence of the wire feed speed wire and pulse time on the joint shear strength in the Nd:YAG laser welding finding that the high wire feed speed and high welding energy attained by expansion pulse time resulted in higher filler metal supply, proved to positively influence the joint strength.

Campana et al. [10] considered aluminium foams laser beam welding with simultaneous foaming a mixture of compacted aluminium alloy powders and a blowing agent deposited into 
the welding groove to obtain porosity of the joint that would be comparable to that of the joined foams.

The findings of conducted research [11] allowed to propose a way of modifying the surface layer of aluminium foams so as to decrease porosity of the edges to be welded. The process of foam edges preparation for welding included plasticisation by means of heating the surfaces to be welded with welding arc, followed by pressing the surfaces down in order to reduce their porosity (Fig. 2). Mechanical densification of the surface of aluminium foams conducted in an elevated temperature decreases the porosity from $80 \%$ up to $20 \%$ with a compression at the depth of up to $10 \mathrm{~mm}$. Laser and GTA welded joints (Fig. 3) whose tensile strength was higher than that of the foam were produced. In all cases of tensile tests, the damage in the samples occurred in the composite foam, outside the area of the joint.

a)

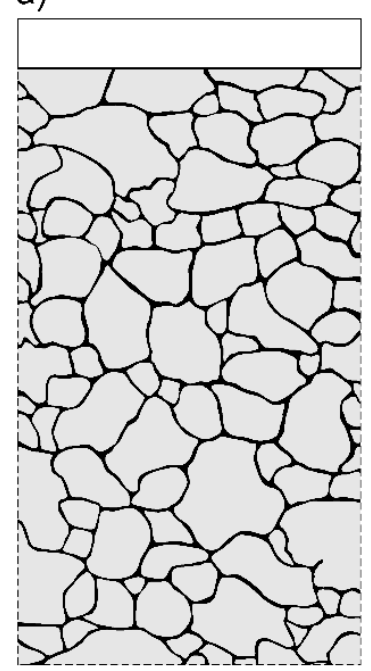

b)

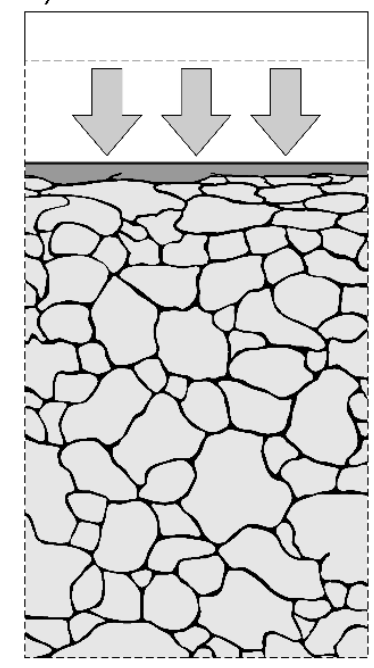

c) Metal fract., $\%$

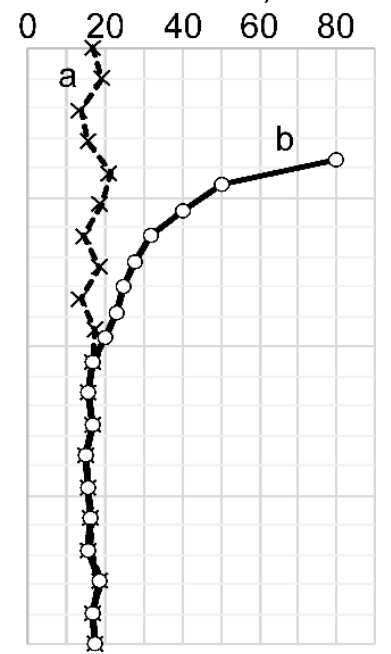

Fig 2. Structure of AISig-SiC10 foam with a densified edge as a result of pressing after heating: foam before densify (a); foam after densify (b); porosity distribution (c)

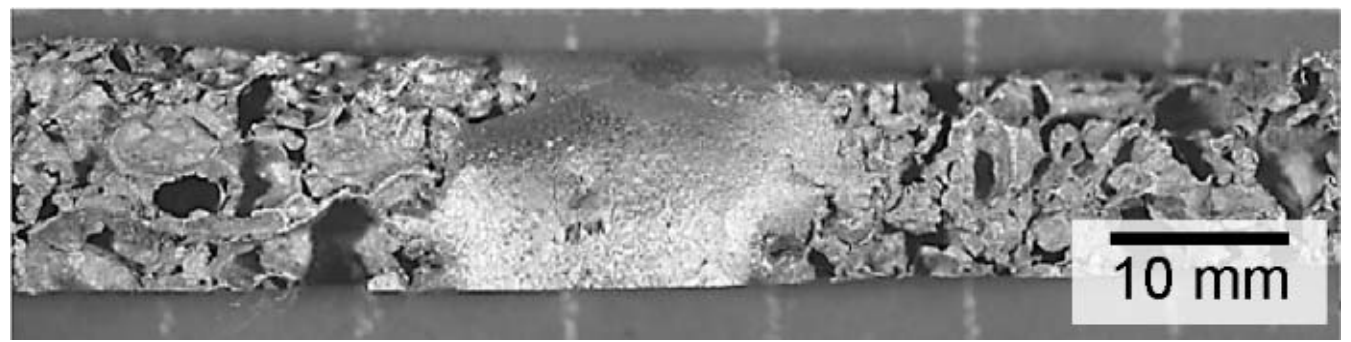

Fig. 3. AISi9-SiC10 foam, GTA, I-bevelled weld macrostructure

\section{SOLDERING}

The preparation of foam edges for flame or hot-air soldering requires cleaning the both the products of cutting and the layer of oxides off the surface. In the case of aluminium foams, porous structure of the surface that contains irregularly-shaped pores makes it difficult to clean the surfaces carefully before soldering. In such a case, the desired results can be obtained with chemical cleaning.

Porous structure of foams makes results in the size of soldering gap being irregular and 
changeable as well as restrains even distribution of solder and flux in the area of the joint. The capillarity of the gap surrounded by the pores is highly reduced. When open pores are in question, the flux penetrates into the foam, and non-corrosive fluxes have to be used in order to solve this problem.

Bernard et al. [12] used S-Bond 220, SnAg4Ti4 alloy for soldering aluminium foams and shown that weight-related maximum load of investigated sandwich structures was not so favourable in case of soldered joint as in the case of gluing, welding, or riveting combined with gluing.

There is no data source for the AlSi9-SiC10 composite foam soldering. Lu et al. [13] tried to solder nonporous AlSi9-SiC10 composite profiles. They came across difficulties in joining resulting from the absence direct wetting of a surface with the conventional solders.

In order to produce a soldered joint that would display the required properties of composite AlSi9+SiC10 foams, it is necessary to solve the problem of low wettability of the foam surface by the solder and the problem of straining of the foam pores as a result of heating the foam surface up to soldering temperature.

Wan, Huang and Ubertalli et al. [14]-[16] used specialized surface activation techniques based on surface self-abrasion fluxless soldering and Zn-based joining materials have obtained satisfactory joint results.

The rise in soldering temperature exerts a positive influence on wettability, but it also results in foam undergoing deformation more often. In order to solve these problems, a few soldering attempts were conducted, which involved the following: determining the method of surface preparation, heating (propane-air flame and hot air flow), dosing filler metal when using ZnAl22, ZnAl4, ZnAl2 solders that have zinc for their major component (Tab. 1).

An important part of the preparation of the foam surface for soldering consists in applying a layer of solder onto the surface in order to close the pores. The best result in terms of applying solder onto the AlSi9-SiC10 aluminium foam surface was obtained when ZnAl22 solder with flux core was used (Fig. 3), since it exhibited a good wettability and spreadability [17]. Under the influence of hot air flow, the solder spread on the foam surface, creating a continuous layer that adhered to the foam well and filled the pores (Fig. 4). The soldering gap of the butt-soldered joint in AlSi9-SiC10 foam was fully filled with the filler metal (Fig. 4).

Soldering attempts were conducted on AlSi9-SiC10 foams of $80 \%$ porosity. The edges to be soldered were prepared with the methods of wire electrical discharge machining and water jet cutting with an abrasive that are considered to produce the best effects in such case. Soldered butt joints were produced on I-bevelled samples with the use of the solders shown in Tab. 2. Flame and hot air heating was employed. Contrary to flame heating, hot air heating guaranteed that the walls of foam cells would not undergo deformation. The temperature of soldering with $\mathrm{ZnAl} 22$ alloy $-70^{\circ} \mathrm{C}$ higher than the temperature of soldering with $\mathrm{ZnAl} 4$ alloy - gave rise to considerable deformations in the walls of foam cells.

Table 2. Solders used in the experiment

\begin{tabular}{cccc}
\hline Filler metal & $\begin{array}{c}\text { Chemical composition } \\
\text { approximately, \% wt. }\end{array}$ & Form & $\begin{array}{c}\text { Soldering temperature } \\
\text { applied, }{ }^{\circ} \mathrm{C}\end{array}$ \\
\hline ZnAl4 & $96 \% \mathrm{Zn}, 4 \% \mathrm{Al}$ & $\begin{array}{c}\text { flux covering } \\
\text { rods }\end{array}$ & 410 \\
ZnAl22 & $78 \% \mathrm{Zn}, 22 \% \mathrm{Al}$ & flux cored wire & 485 \\
S-Bond 220 & $92 \% \mathrm{Sn}, 4 \% \mathrm{Ag}, 4 \% \mathrm{Ti}$ & solid wire & 250 \\
\hline
\end{tabular}



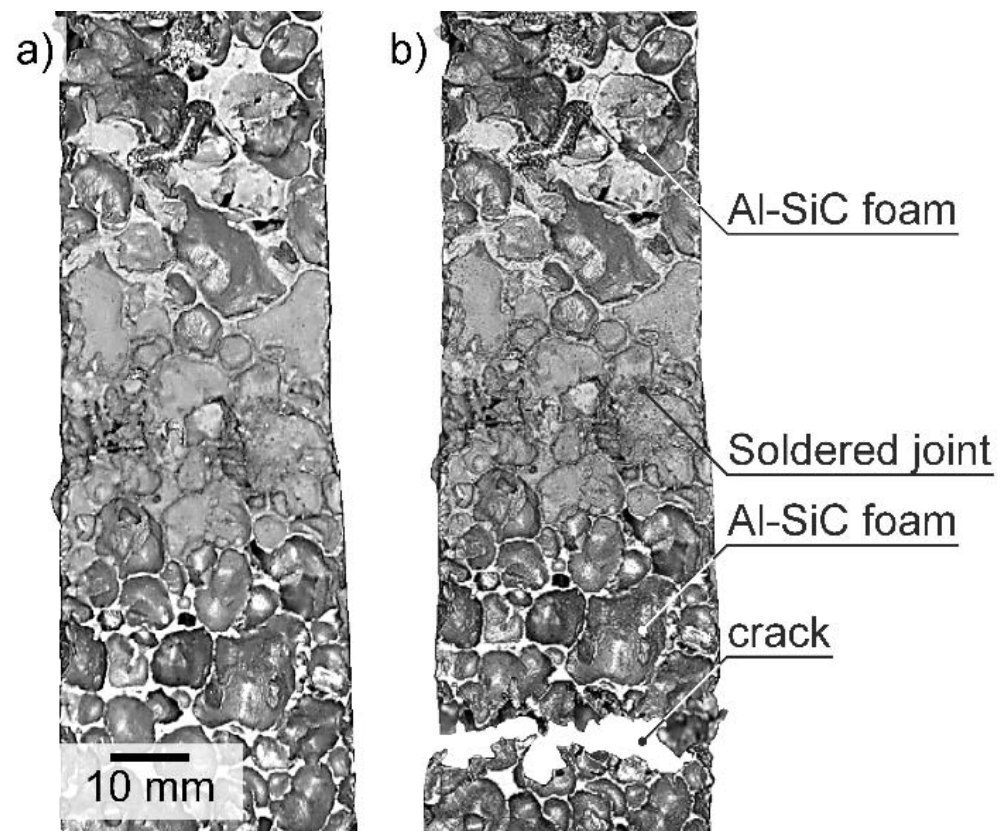

Fig. 4. Structure of a soldered joint in AISi9-SiC10 foam, soldered with ZnAl4 solder, before (a) and after (b) tensile shear strength test

The best results in terms of soldering AlSi9-SiC10 composite foams were obtained using S-Bond 220 solder that has tin for the major constituent. What is characteristic of the solder is the fact that its fusion temperature more than $200^{\circ} \mathrm{C}$ lower than the fusion temperature of the ZnAl22 solder. Due to low its spreadability, the solder has to be spread out mechanically with the aid of friction. S-Bond can react with many compounds, including oxide which can be present on the surfaces of the joined elements.

In the present research, the solder was applied on both joined surfaces separately. The surfaces were then pressed against and moved against each other in order to rub the filler metal into the pores and rip the layers of oxides off the joined surfaces. Depending on the length of the process, the attempts of soldering composite foams with the use of S-Bond 220 solder and hot air as a heat source produced joints of varying structures. Shorter soldering times (up to $30 \mathrm{~s}$ ) and less energetic mechanical friction of the solder covering the surface of the foam into the pores produced joints of adhesive type. Long soldering times (up to $300 \mathrm{~s}$ ), coupled with intensive mechanical friction of the filler metal into the surface of the foam fostered the emergence of intermetallic boundary layers. In this case, the joint consisted of a thin layer rich in silver and a thicker one, rich in titanium and containing intermetallic compounds: $\mathrm{Ag}_{\mathrm{x}} \mathrm{Al}_{\mathrm{y}}\left(\mathrm{Ag}_{2} \mathrm{Al}, \mathrm{Ag}_{3} \mathrm{Al}, \mathrm{Ag}_{5} \mathrm{Al}_{3}\right)$, TiC. Result of EDS and XRD investigations of the AlSi9-SiC10 composite foams joint (Fig. 5-8) laid the foundations to the proposed scheme of the structure of a joint soldered with S-Bond 220 in AlSi9-SiC10 composite foam (Fig. 59.). 

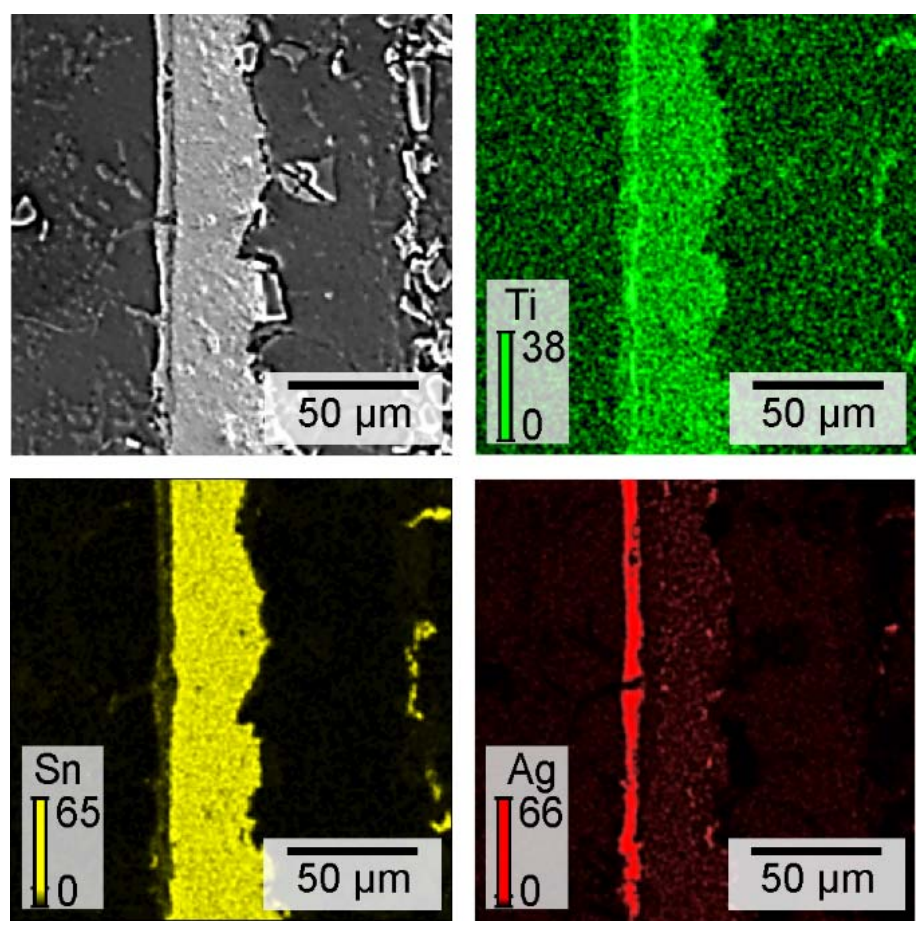

Fig. 5. Microstructure and EDS mapping of AISi9-SiC10 composite foam joint, soldered with S-Bond 220 (SEM-BSE)

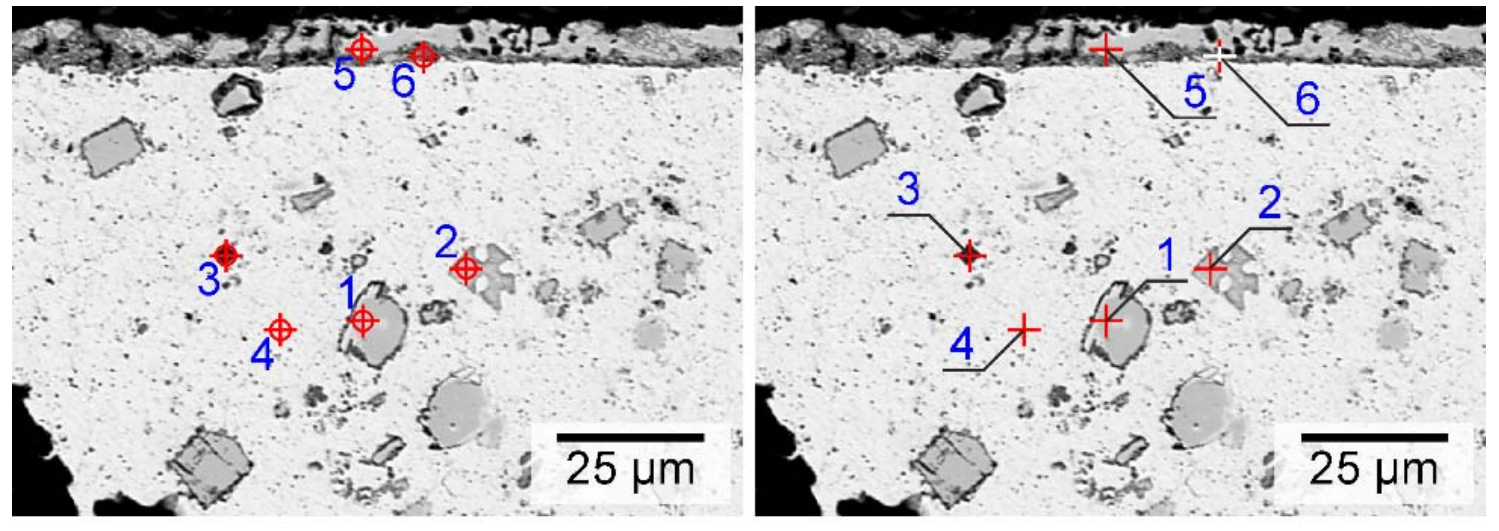

\begin{tabular}{|c|c|c|c|c|c|c|c|c|c|c|c|c|c|c|}
\hline \multirow{2}{*}{ Point } & \multicolumn{10}{c|}{ Element percent weight } \\
\cline { 2 - 17 } & $\mathrm{C}$ & $\mathrm{N}$ & $\mathrm{O}$ & $\mathrm{Al}$ & $\mathrm{Si}$ & $\mathrm{Sc}$ & $\mathrm{Ti}$ & $\mathrm{V}$ & $\mathrm{Cr}$ & $\mathrm{Mn}$ & $\mathrm{Fe}$ & $\mathrm{Ga}$ & $\mathrm{Ag}$ & $\mathrm{Sn}$ \\
\hline 1 & 1.06 & & & 0.26 & & & 32.1 & & & & & 0.02 & 0.70 & 65.80 \\
\hline 2 & 1.62 & & 30.03 & 0.29 & & 0.72 & & & & & & & & 62.61 \\
\hline 3 & 2.60 & & & 47.62 & 7.59 & & 0.39 & 0.27 & 1.43 & 4.60 & 19.71 & & & 15.92 \\
\hline 4 & 0.92 & & 5.20 & 0.30 & & & & & & & & & & 93.60 \\
\hline 5 & 1.43 & 1.92 & 2.95 & 8.54 & 0.84 & & & & & & & & 58.30 & 26.04 \\
\hline
\end{tabular}

Fig. 6. Results of SEM-EDS microanalysis of a joint in AISi9-SiC10 foam, soldered with S-Bond 220 


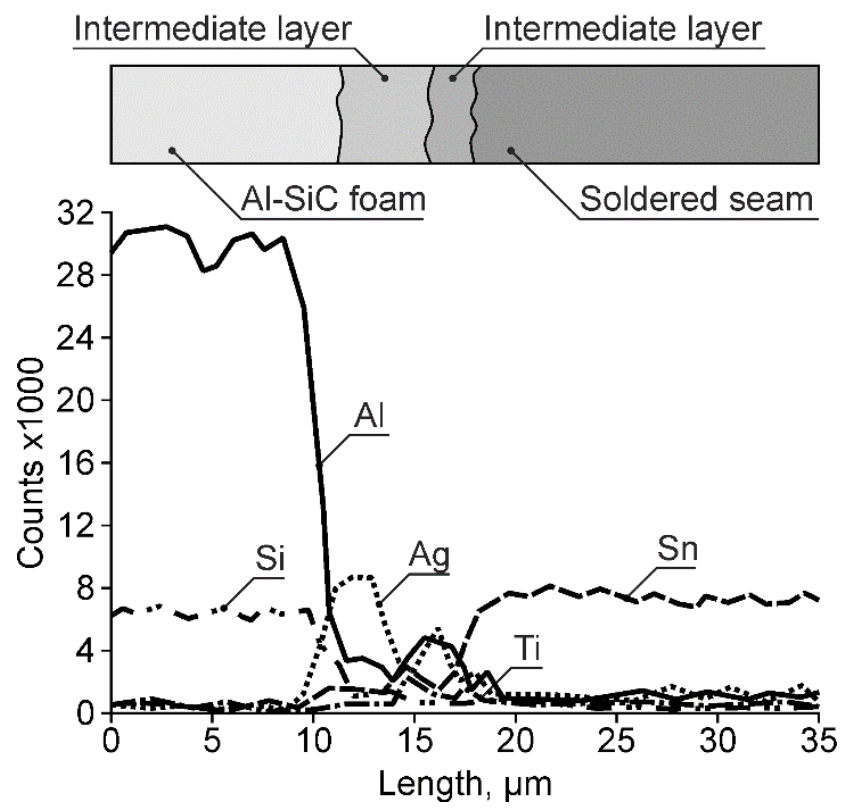

Fig. 7. Line-scan EDS analysis of the interfacial area of AISi9-SiC10 - S-Bond 220 solder interface

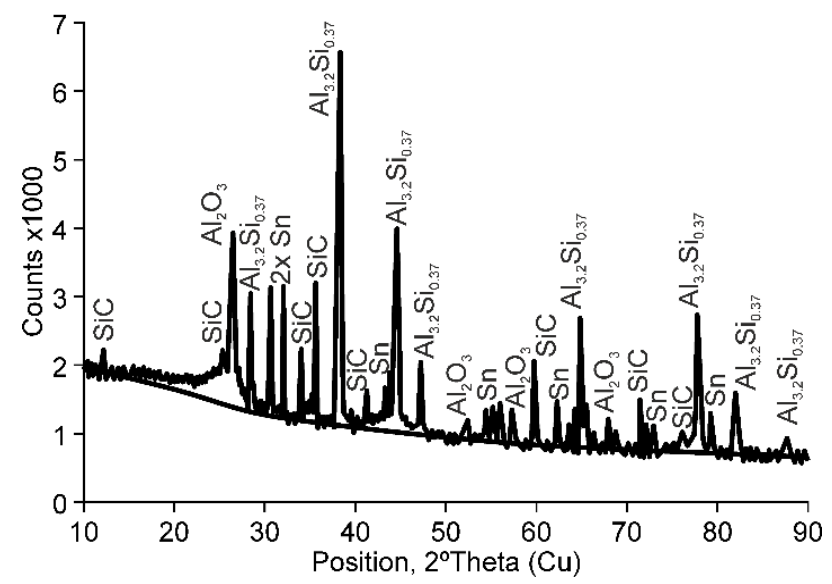

Fig. 8. Diffractogram from an XRD analysis of a joint in AISi9-SiC10 foam, soldered with S-Bond 220

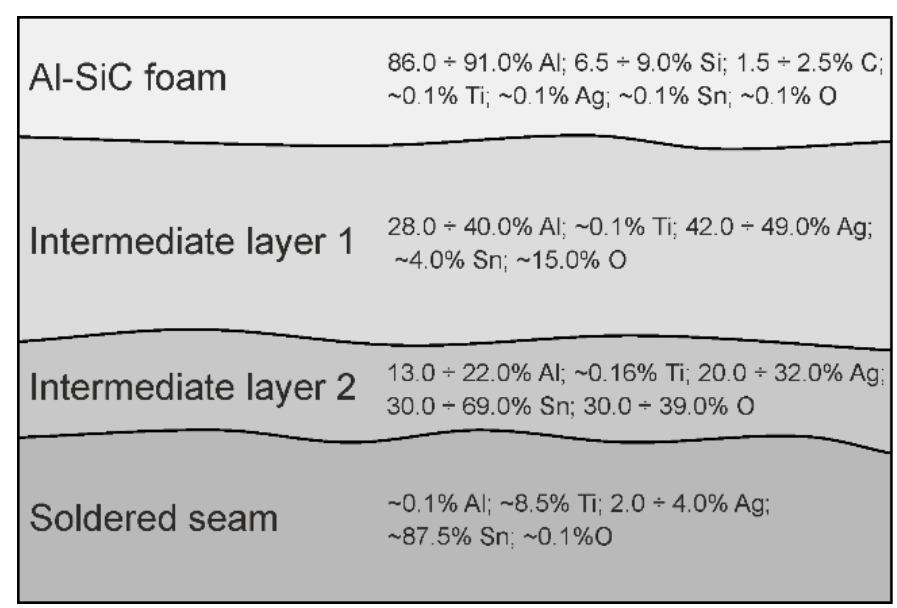

Fig. 9. Graphical representation of the structure of a joint in AISi9-SiC10 foams, soldered with S-Bond 220 filler metal 


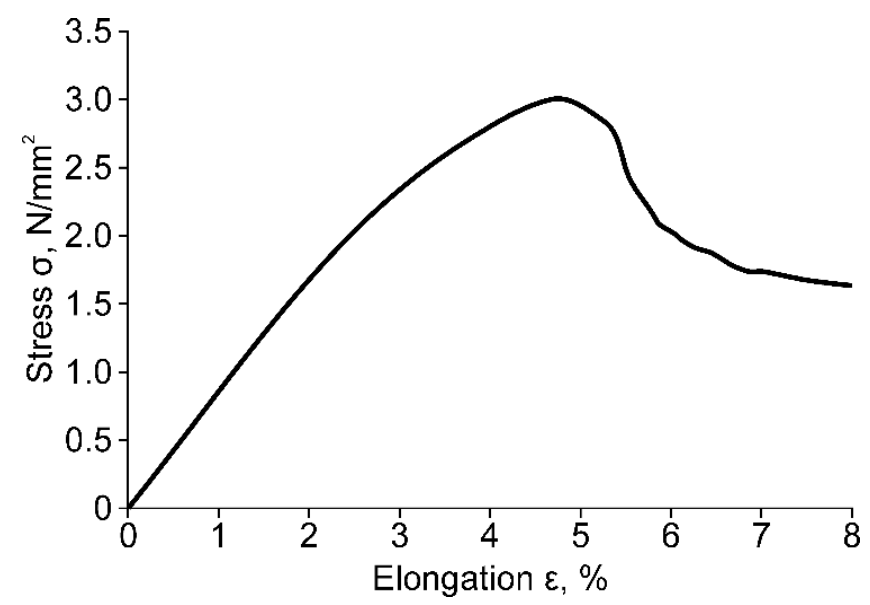

Fig. 10. Example stress-strain curves obtained in a static tensile test for $80 \%$ porosity AISi9-SiC10 foam specimens soldered with S-Bond 220

Typical for all soldered joints example stress-strain curves obtained in a static tensile test for $80 \%$ porosity AlSi9-SiC10 foam specimens soldered with SnAg4Ti4 is presented on Fig. 10. The tensile strength of all soldered joints were higher than that of the foam itself, while any damage in soldered samples occurred outside the area of the joint like in the case of ZnAl4 joints (Fig.10). The tests showed that it is possible to solder aluminium foams using the solders proposed. It was demonstrated that the metallurgical properties of solders used do exert influence on the course of the soldering process, but the form of solder is no less important - the use of flux-cored wire and low fusion temperature of the solder, which characterise of the S-Bond 220 filler metal.

\section{GLUING TECHNIQUE}

Adhesives are characterised by low specific gravity in comparison to welded and soldered joints. For this reason, they are the best choice for light constructions working in temperatures less than $100^{\circ} \mathrm{C}$.

The porosity tests conducted with a gravimetric method determined the value of porosity on the level of $91,1 \%$, with a standard deviation of $0,465 \%$. The gravimetric method employed produced repeatable results, proving its effectiveness.

The analysis of the mechanical properties of composite foams (Fig. 10) shows low values of tensile stress at the moment of sample rupture. Such results allow for the use of a wide variety of adhesives which may possess unique properties with regard to temperature and corrosion resistance, vibration damping, impact strength, etc.

The available structural adhesives were compiled into a database containing 54 technological variables characterising a given adhesive. Adhesives that fulfil the strength criterion exhibit a wide range of technological, rheological and performance properties. Therefore, individual properties of a joint can be designed, depending on operating conditions. Loctite Hysol 3421 adhesive was selected for further tests, since it fulfilled the complex criteria with regard to high mechanical strength and favourable technological parameters. In order to carry out weight optimisation of the designed joints, it is necessary to analyse of foam structure and conduct shearing tests in order to reveal strength properties of the foams. A varying degree of penetration of the adhesive into the foam structure was observed in the joints obtained. The degree of penetration depends on the size of the open pores. When the thickness of the adhesive applied onto the surface is constant, the pores are 
not completely filled. A very thin layer of adhesive can be found in the place where the elements of the foam and the sheet plate meet.

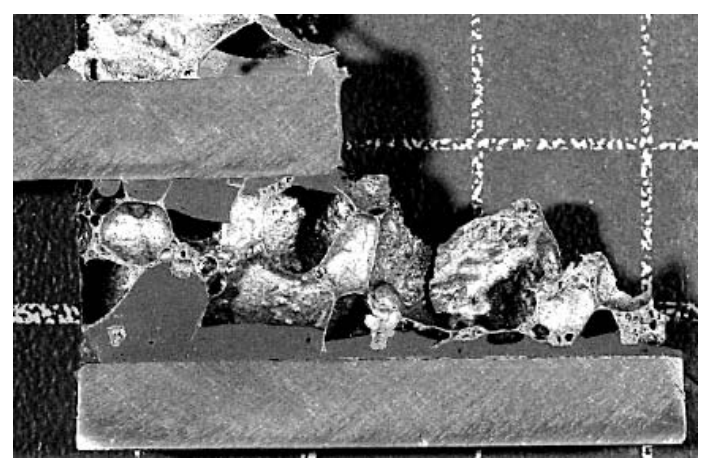

Fig. 11. Infiltration of the AISi9-SiC10 foam with adhesive

The glued joint has a characteristic band structure extending along the direction of spreading of the adhesive. The structure emerges in the course of pressing the elements of the joint against each other. During microstructural analysis, delaminations were observed along the line of spread bands. The band structure is located at the spots where the protruding elements of the foam caused high mixing turbulence of the adhesive (Fig. 11). Delaminations constitute a weakening and run a risk that the adhesive cracking and undergoing decohesion. In the course of microscopic evaluation, decohesion cracks were not observed. Due to their shape and size, the pores located in the adhesive-bonded joint do not bear any considerable influence on the strength of the joint.

Due to their, developed and open structure, porous aluminium foams constitute a type of material that does not require making spaces in adhesive-bonded joints. The spacing recommended by manufacturers equals $0.2 \div 0.5 \mathrm{~mm}$. When gluing foams in technological conditions is in question, such spacing is difficult to obtain due to problems resulting from inserting spacers, e.g. in the form of beads, between the joined surfaces. Test results [18], [19] allowed to observe that the amount of adhesive that penetrates into the open pores on the surface of the joined elements made of aluminium foam is sufficient to ensure the required strength.

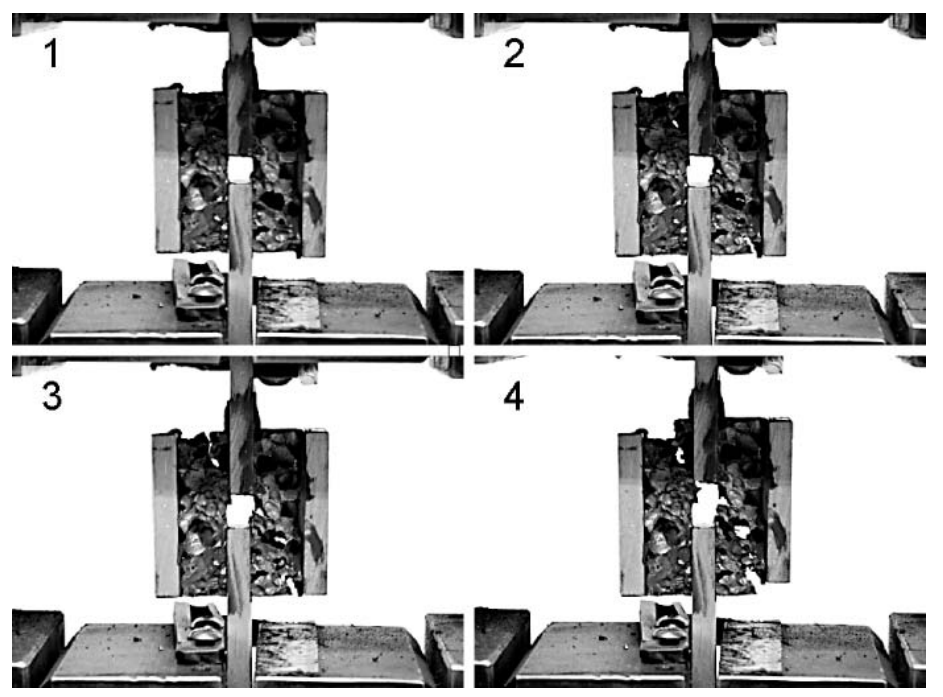

Fig. 12. The sequence of tensing a glued sample, showing the way in which the joint was destroyed. The resulting ductile fracture was accompanied by a visible strain of the foam in the plane where the concentration of the material was the lowest 


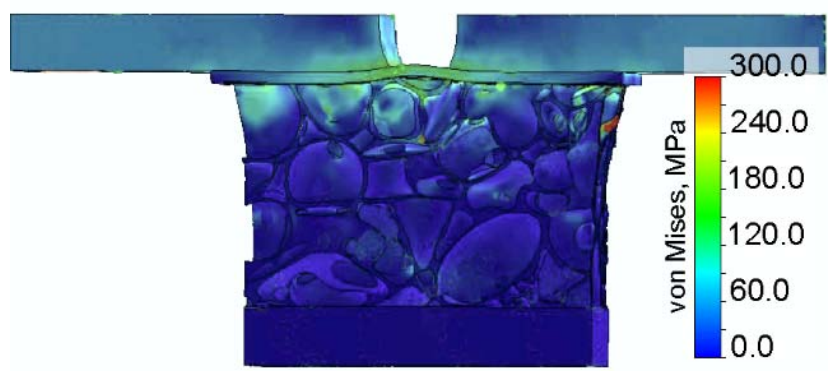

Fig. 13. Results of numerical simulations of stresses in the glued joint of composite AISi9-SiC10 foam

The course of the shear test of glued joints is not considerably different from the tests on welded and soldered joints (Fig. 10). Irrespective of the thickness of the adhesive layer, it is the elements of the foam that get destroyed.

The numerical simulations conducted for all types of joints analysed in the article (Fig. 13) demonstrated an increased state of stress of the metallic foam in the area adjacent to the joint.

Photographic registration of a sequence of images of the strength test sample in the course of testing allowed to reveal the causes of fracture (Fig. 12). In the joints tested, one could observe a ductile fracture of the sample that was accompanied by a visible strain of the foam in the plane where the concentration of metal was the lowest.

The structural and strength analysis make it possible to state that it ultralight constructions can be made with metallic composite foams and adhesive when the minimum thickness of the joint is maintained. In industrial conditions, it is very difficult to fulfil that requirement without producing a bearing surface on the surface of foam with a developed open porosity beforehand.

Modern adhesives guarantee shear strength over $40 \mathrm{MPa}$ and allow for a working temperature exceeding $200^{\circ} \mathrm{C}$. Gluing composite AlSi9-SiC10 foams involves a special method of edge preparation producing a bearing surface that closes the pores.

The new innovative method of modification of the composite foam surface was proposed. The method depends on, that two-component adhesive composition with a strictly defined thickness, derived from previously prepared prepreg, in the form of two outer layers of Teflon fabric and one main internal layer made of epoxy adhesive (Fig. 14).

The bearing surface obtained can be glued with the available structural adhesives, once it is abraded with corundum abrasive. Narrow tolerance of the joint thickness is achieved with the use of spacing elements in the form of glass beads of $0.2 \mathrm{~mm}$ diameter. After the strength and mass analysis, the last of the above-described solutions is selected for further consideration (solution based on the use of a prepreg). Such technology makes it is possible to produce bearing surfaces that are $0.2 \mathrm{~mm}$ thick.
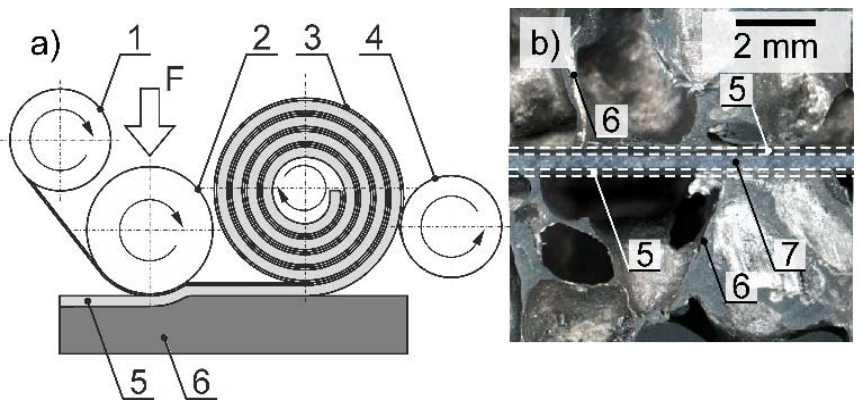

Fig. 14. Preparing a bearing surface in aluminium foam by means of applying a thin layer of adhesive, unfolded from a previously prepared prepreg (a), section of $0,2 \mathrm{~mm}$ thick bearing surface (b); 1,4 - rollers winding teflon; 2 - roll forming the surface; 3 - prepreg; 5 - bearing surface; 6 - aluminium foam; 7 -adhesive 


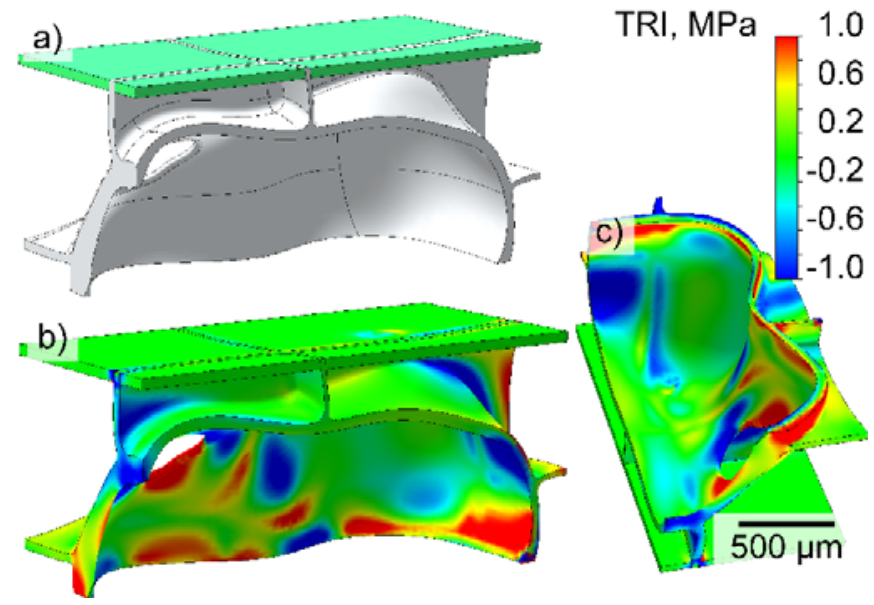

Fig. 15 Analysed with regard to the stress distribution a fragment of a glued joint with $0.2 \mathrm{~mm}$ thick bearing surface (a); stress distribution in bearing surface (b); stress distribution in foam (c)

The majority of stresses in a glued joint where such surface was applied concentrate in the thin walls of the foam (Fig. 15) is in line with the articles [20]-[24]. Despite the minimum amount of adhesive, the stress distribution in the joint is favourable for the filler. The glued joints produced are characterised by a higher tensile strength than the foam itself. The damage in the glued sample occurred in the foam, outside of the area of the joint.

\section{CONCLUSIONS}

Edge preparation in the processes of welding of AlSi9-SiC10 foams is decisive for the depth of filler penetration into the foam.

The degree of penetration of wall cells also depends on the influence of a joining technique on the deformation of the foam structure and amounts to about $5.0 \mathrm{~mm}$ during welding, $3.0 \mathrm{~mm}$ during soldering, $0.2 \mathrm{~mm}$ in the process of gluing.

Because of its high heat input welding is the most difficult technique of joining AlSi9SiC10 foams due to the mass of a joint and the necessity to increase the density of the foam surface mechanically. Soldering AlSi9-SiC10 foams creates much smaller problems that arise from the effects the heat has on the cellular structure of the foam and is recommended for AlSi9-SiC10 foams elements working in higher temperatures.

Gluing in accordance with the method proposed is the most favourable method of joining AlSi9-SiC10 foams that ensures minimum filler penetration, lack of thermal effects on the foam structure and high tensile and compression strengths which are higher than these of the joined material. Limitation for gluing of AlSi9-SiC10 foams elements is temperature in which they are working.

\section{ORCID}

Adam Sajek: 0000-0003-0126-2654

Jerzy Nowacki: 0000-0001-5728-7266 


\section{REFERENCES}

1. Kathuria Y. P., Nd-YAG laser assisted aluminum foaming, J. Mater. Process. Technol., 142(2), (2003) 466-470.

2. Ashby M. F., Evans A., Fleck N., Gibson L. Hutchinson J.W., Wadley H. N., Metal foams: a design guide. Butterworth-Heinemann, 2000.

3. Dunn B. D., Spacecraft Manufacturing-Failure Prevention and the Application of Material Analysis and Metallography, in Materials and Processes: for Spacecraft and High Reliability Applications, Springer International Publishing, 2016, 115-245.

4. Su L., Liu H., Yao G., and Zhang J., Experimental study on the closed-cell aluminum foam shock absorption layer of a high-speed railway tunnel, Soil Dyn. Earthq. Eng., 119(2) (2019) 331-345.

5. Uzay C., Geren N., Boztepe M. H., Bayramoglu M., Bending behavior of sandwich structures with different fiber facing types and extremely low-density foam cores, Mater. Test., 61(3) (2019) 220-230.

6. Bucher T., Laser Forming of Metal Foam: Mechanisms, Efficiency and Prediction, Columbia University, 2019.

7. Jiang Z. Y., Qu Z. G., Lithium-ion battery thermal management using heat pipe and phase change material during discharge-charge cycle: A comprehensive numerical study, Appl. Energy, 242(2) (2019) 378-392.

8. Dai Z., Nawaz K., Park Y., Chen Q., Jacobi A. M., A Comparison of Metal-Foam Heat Exchangers to Compact Multilouver Designs for Air-Side Heat Transfer Applications, Heat Transf. Eng., 33(1) (2011) 21-30.

9. Burzer J., Bernard T., W. Bergmann H., Joining of aluminium structures with aluminium foams, in Porous and Cellular Materials for Structural Applications, Vol. 521, San Francisco, California, U.S.A.: Material Research Society, 1998, 160-165.

10. Campana G., Ascari A., Fortunato A., Laser foaming for joining aluminum foam cores inside a hollow profile, Opt. Laser Technol., 48, (2013) 331-336.

11. Nowacki J. Moraniec K., Welding of metallic AlSi foams and AlSi-SiC composite foams, Arch. Civ. Mech. Eng., 15(4), (2015) 940-950.

12. Bernard B. T., Bergmann H. W., Haberling C., Joining Technologies for Al-Foam \pm Al-Sheet Compound Structures, Adv. Eng. Mater., 10, (2002) 798-802.

13. Lu J., Mu Y., Luo X., Niu J., A new method for soldering particle-reinforced aluminum metal matrix composites, Mater. Sci. Eng. B Solid-State Mater. Adv. Technol., 177(20), (2012) 17591763.

14. Wan L., Huang Y., Huang T., Lv Z., Feng J., Interfacial behavior and mechanical properties of aluminum foam joint fabricated by surface self-abrasion fluxless soldering, J. Alloys Compd., 671, (2016) 346-353.

15. Huang Y., Gong J., Lv S., Leng J., Li Y., Fluxless soldering with surface abrasion for joining metal foams, Mater. Sci. Eng. A, 552, (2012) 283-287.

16. Ubertalli G., Ferraris M., Bangash M. K., Joining of AL-6016 to Al-foam using Zn-based joining materials, Compos. Part A Appl. Sci. Manuf., 96, (2017) 122-128.

17. Nowacki J.. Moraniec K., Evaluation of Methods of Soldering AlSi and AlSi-SiC Particle Composite Al Foams, J. Mater. Eng. Perform., 24(1), (2015) 426-433.

18. Sajek A., Aluminum foams gluing, Metall. Foundry Eng., 39(2), (2013) 17-24.

19. Nowacki J., Sajek A., Matkowski P., The influence of welding heat input on the microstructure of 
joints of S1100QL steel in one-pass welding, Arch. Civ. Mech. Eng., 16, (2016) 777-783.

20. Nowacki J. Sajek A., Optimizing glue joint of aluminium metallic foams, J. Achiev. Mater. Manuf. Eng., 75(1), (2016) 14-23.

21. Ohsenbrügge C., Marth W., Navarro I., De Sosa Y., Drossel W. G, Voigt A., Reduced material model for closed cell metal foam infiltrated with phase change material based on high resolution numerical studies, Appl. Therm. Eng., 94, (2016) 505-512.

22. Yang F., Niu W., Jing L., Wang Z., Zhao L., Ma H., Experimental and numerical studies of the anti-penetration performance of sandwich panels with aluminum foam cores, Acta Mech. Solida Sin., 28(6), (2015) 735-746.

23. Liu C., Zhang Y. X., Yang C., Numerical modelling of mechanical behaviour of aluminium foam using a representative volume element method, Int. J. Mech. Sci., 118, (2016) 155-165.

24. Lazaro J., Solorzano E., Rodriguez-Perez M. A., Kennedy A. R., Effect of solidification rate on pore connectivity of aluminium foams and its consequences on mechanical properties, Mater. Sci. Eng. A, 672, (2016) 236-246. 